\title{
Situational analysis and reflections on the introduction of advanced practice nurses in Brazilian primary healthcare
}

\author{
Carinne Magnago ${ }^{1^{*}}$ (D) and Celia Regina Pierantoni ${ }^{2}$
}

\begin{abstract}
Background: The shortage of doctors and their unequal distribution serve as challenges to advancing primary healthcare (PHC) and achieving effective universal healthcare coverage in Brazil. In an effort to use nurses' potential more efficiently, the country is investigating the introduction of the advanced practice nurse (APN) into PHC. This paper presents a situational analysis of the practices of Brazilian nurses based on the following components: regulation, practice, and education.

Methods: This is a national multi-method study with triangulated data from a documentary study, a scoping review, and an exploratory study. The regulation component involved the analysis of official normative documents on the regulation of nursing education and nurses' scope of practice. The practice component aimed to identify the practices performed by nurses in Brazilian PHC based on primary studies. The education component intended to identify the practices taught in nursing training based on a survey and interviews with directors of undergraduate nursing programs.
\end{abstract}

Results: Federal legislation in Brazil authorizes nursing graduates to perform a set of advanced practices as part of the PHC nurse's daily routine. They can request and interpret complementary tests and prescribe medication. However, in the local context, municipalities define the scope of this assistance based on technical norms or nursing protocols. Furthermore, this study indicates that undergraduate nursing programs do not fully prepare students to adequately execute these tasks.

Conclusions: In the context of Brazilian PHC, advanced practices have already been implemented and respond to main healthcare demands. Therefore, it is unnecessary to introduce the APN as a new professional category. Upon detecting deficiencies in the training process, the current education model should undergo reforms that seek to incorporate the skills compatible with the regulated advanced practices and in-service training for practicing nurses. Regarding the introduction of APN along international lines, this article presents recommendations that may support the operationalization of a Brazilian APN model.

Keywords: Advanced practice nursing, Primary health care, Scope of practice, Nurse's role, Baccalaureate nursing education, Nursing legislation, Brazil

\footnotetext{
*Correspondence: carinne@usp.br

1 Department of Policy, Management and Health, School of Public Health,

University of São Paulo (FSP/USP), Av. Dr. Arnaldo, 715, São Paulo, SP 01246-904, Brazil

Full list of author information is available at the end of the article
}

\section{Background}

Brazil is a country with continental dimensions that is subdivided into five geographic macroregions (North, Northeast, Midwest, Southeast, and South) with different demographic and socioeconomic conditions and wide internal inequalities [1]. The Brazilian Unified Health original author(s) and the source, provide a link to the Creative Commons licence, and indicate if changes were made. The images or other third party material in this article are included in the article's Creative Commons licence, unless indicated otherwise in a credit line to the material. If material is not included in the article's Creative Commons licence and your intended use is not permitted by statutory regulation or exceeds the permitted use, you will need to obtain permission directly from the copyright holder. To view a copy of this licence, visit http://creativecommons.org/licenses/by/4.0/. The Creative Commons Public Domain Dedication waiver (http://creativeco mmons.org/publicdomain/zero/1.0/) applies to the data made available in this article, unless otherwise stated in a credit line to the data. 
System (SUS), that is oriented toward primary healthcare (PHC), suffers from a shortage, high turnover, and unequal distribution of physicians [2,3], especially in the rural and remote areas of the Northern and Northeastern macroregions. This threatens the population's access to high-quality, definitive care [4, 5]. Approximately 20,000 doctors graduate annually in Brazil, and they are mostly incorporated into private healthcare services in large urban centers [5-7]. Meanwhile, there is a growing number of nurses in the labor market (40,000/year), with greater availability to work in the public healthcare sector, whose services could be more efficiently utilized $[6,7]$. New profiles such as the advanced practice nurse (APN) may be instrumental in advancing Brazilian PHC and achieving universal healthcare coverage [8].

The APN has specialized knowledge, complex decision-making skills, and clinical skills for a broader scope of practice, and their characteristics are shaped by the context in which they are certified to practice [9-12]. In PHC, the APN operates with an expanded scope of practice that incorporates the physician's tasks and involves either substituting or complementing the physician's work [9]. In the United States and Canada, advanced practices include diagnosing and treating acute and chronic diseases, ordering and interpreting diagnostic tests, prescribing drugs without a physician's supervision, and referring patients to specialists [9, 13, 14]. Mirroring the experiences of these countries, Brazil is investigating the possibility of introducing the APN into primary care [15].

Given the incipience of national studies that are oriented toward the implementation of the APN in the SUS, this study analyzes the practices of Brazilian nurses based on three components-regulation, practice, and education-to identify and compare the nature of authorized practices, practices developed in $\mathrm{PHC}$, and practices taught in undergraduate nursing programs.

\section{Methods}

We conducted a national multi-method study that triangulated primary and secondary data, in order to analyze the problems, conditions, and opportunities involved in introducing APN in Brazil. For the regulation component, we analyzed a set of official normative documents that detail the regulation of nursing education and the nurse's scope of practice in the context of PHC. We retrieved these documents in March 2021 from the websites of the Ministries of Health and Education and the Federal Nursing Council $(\mathrm{COFEN})^{1}$ and conducted a qualitative analysis of their content.

For the practice component, we performed a scoping review [16] of primary studies conducted on nurses practicing in PHC in Brazil to identify the practices effectively performed by these professionals. In March 2021, we used a standard search strategy to consult different scientific databases, and 22 of the 780 studies found were selected for analysis. This set of studies included 3618 PHC nurses and described more than 90 activities performed in daily professional practice (More information can be found in Additional File 1). We presented the results of the review in the form of a narrative synthesis.

We examined the education component based on a national exploratory study that conducted telephone surveys and face-to-face interviews with directors of undergraduate nursing programs; some of these data have been previously published [17-19]. In this study, we assessed the data that revealed the specific practices that nursing programs had taught their students. The telephone surveys were conducted with 94 directors in the first semester of 2016, after a sample calculation based on the total number of programs in 2013 [17]. We used descriptive statistics to analyze the data. Between November 2015 and March 2017, face-to-face interviews were conducted with 16 directors who did not participate in the telephone survey [18]. The interviews were recorded, transcribed, and submitted for content analysis. All ethical aspects were observed in accordance with Brazilian legislation.

Triangulation involved fusing the data sets for each stage, synthesizing the results in an explanatory structure, and generating a final discussion. During triangulation, inferences and recommendations were extracted from the findings of the combined results for a better understanding of the phenomenon in question [20].

\section{Results \\ Regulation}

In Brazil, the Federal Government has exclusive legislative power over professions and has the power and duty to supervise the activities of professions. As statecontrolled entities, healthcare professions are regulated by three branches: the legislative branch creates laws for professional practice, the executive branch provides curricula and implements health policies, and the judiciary branch makes decisions in the context of legal disputes. Another important source of regulation is the

\footnotetext{
${ }^{1}$ This is the professional nursing council in Brazil-an organization created by federal law for the purpose of regulating, standardizing, and supervising the profession it represents.
} 
Table 1 Educational guidelines for the Bachelor's in Nursing degree in Brazil

\begin{tabular}{|c|c|}
\hline Graduate profile & Professional with a generalist, humanistic, critical, and reflective training to work at all healthcare levels \\
\hline Qualifications and emphases & $\begin{array}{l}\text { Training must meet the healthcare system's demands and social health needs and ensure comprehensive, humanized } \\
\text { care and quality and emphasize the recognition of the right to health in technical and scientific performance and in } \\
\text { health promotion, maintenance, prevention, protection, and recovery }\end{array}$ \\
\hline General skills and abilities & $\begin{array}{l}\text { Healthcare; decision-making; communication; leadership; administration and management; permanent education; and } \\
\text { contextualized technical/scientific, ethical/political, and social/educational skills }\end{array}$ \\
\hline \multirow[t]{8}{*}{$\begin{array}{l}\text { Specific skills corresponding } \\
\text { to primary care }\end{array}$} & $\begin{array}{l}\text { - Acknowledge health as a right and act in a way to guarantee comprehensive care, understood as the coordinated, } \\
\text { continuous set of preventive and curative individual and collective actions and services required for each case at all } \\
\text { levels of the system's complexity }\end{array}$ \\
\hline & - Be active in comprehensive healthcare programs for children, adolescents, women, adults, and the elderly \\
\hline & $\begin{array}{l}\text { - Be able to diagnose and resolve health problems, communicate, make decisions, intervene in the work process, work in } \\
\text { a team, and face constantly changing situations }\end{array}$ \\
\hline & $\begin{array}{l}\text { - Respond to regional health specificities through strategically planned interventions in health promotion, prevention, } \\
\text { and rehabilitation, paying full attention to the health of individuals, families, and communities }\end{array}$ \\
\hline & - Assume an ethical, humanistic, and social commitment to multiprofessional healthcare work \\
\hline & - Act in different scenarios of professional practice based on the premises of clinical and epidemiological models \\
\hline & - Identify the population's individual and collective health needs, their conditions, and determinants \\
\hline & $\begin{array}{l}\text { - Intervene in the health-disease process and take responsibility for the quality of nursing assistance/care in its different } \\
\text { healthcare levels with health promotion, prevention, protection, and rehabilitation actions from the perspective of } \\
\text { comprehensive care }\end{array}$ \\
\hline Curricular contents & $\begin{array}{l}\text { Biological and Social Foundation of Nursing (Morphology, Physiology, Pharmacology, Pathology, Cellular and Molecular } \\
\text { Biology, Nutrition, Public Health and Environmental Health/Ecology); Human Sciences (Anthropology, Philosophy, Soci- } \\
\text { ology, Psychology, Communication, and Education); Fundamentals of Nursing; Nursing Assistance; Nursing Administra- } \\
\text { tion; Nursing Education }\end{array}$ \\
\hline Internships & $\begin{array}{l}\text { The minimum workload for the supervised curricular internship must total } 20 \% \text { of the total course load. In addition to } \\
\text { the theoretical and practical content developed throughout the nurses' training, nursing programs are required to } \\
\text { include in their curriculum a supervised internship in general and specialized hospitals, outpatient clinics, primary care } \\
\text { service network, and communities }\end{array}$ \\
\hline Duration & Nursing programs must have a minimum course load of $4,000 \mathrm{~h}$ and a minimum limit of five years \\
\hline
\end{tabular}

professional councils, which are federal autarchies, as recognized and authorized by the State, that have the power to supervise and discipline professional practice [21].

Nursing is one of the 24 healthcare professions currently under regulation in Brazil, and the right to exercise this profession is guaranteed by Law No. 7.498/1986 [22], which establishes that nursing can only be practiced by nurses, nursing technicians, nursing assistants, and midwives. It also stipulates that nursing activities can only be performed by persons who are legally qualified and registered with the regional professional council that has jurisdiction in the state where they practice. For nurses, this qualification is granted through a bachelor's degree issued by an institution certified by the Ministry of Education

Nurses' educational preparation must follow federal guidelines that specify training should prepare students to become professionals with a generalist profile who can cope with the main health problems of the nation [23]. Given the specificities of the SUS, training should include developing skills that apply in different healthcare services, particularly those required by PHC (Table 1 ).
According to Law 7.498/1986 [22], the nurse is responsible to perform all nursing activities, while managerial practices and activities of greater clinical complexity are exclusive to them. With the exception of these exclusive activities, this legal provision does not detail the actions included within the nurse's scope of practice. This may be because part of a nurse's functions has been historically legitimized, as it is one of the first healthcare professions to be regulated in Brazil. Meanwhile, many practices, usually reserved for nurses, have been incorporated by other professions (such as nutrition and psychology), thus resulting in a need to review nurses' attributions.

This dynamic is permanent in the world of healthcare professions, largely in part because professional councils have normative and regulatory competence that allows them to define the activities that can be performed by their professionals [21]. Between 1975 and 2020, COFEN published more than 300 provisions that ensure, authorize, or prohibit practices. These provisions often trigger jurisdictional disputes over particular or exclusive acts, especially in regard to medicine, which has solid ties with parliamentary leaders and constantly attempts to restrict 
other professions' scope of practice to preserve its exclusive practice areas.

In the context of PHC, nursing activities must take into account the epidemiological aspects and guidelines for the healthcare practices set forth in Law 7.498/1986 [22] and in the Brazilian primary care policy [24] that describes the general duties of those who comprise the multiprofessional healthcare teams. More detailed functions are contained in guidelines, manuals, and thematic journals that specify care for particular groups (e.g., women's health, children's health, chronic diseases) and are updated periodically based on new evidence. From this perspective, nurses have legal prerogatives for expanded assistance in Brazil: in PHC, they can request complementary tests, prescribe medication, and refer patients to other professionals and services. However, in the local context, municipalities define the scope of this assistance based on technical norms or specific nursing protocols.

Table 2 presents a summary of the set of authorized practices for Brazilian nurses.

\section{Practice}

The practices performed by nurses in PHC can be divided into four interdependent dimensions: clinical, managerial, health surveillance, and educational. The investigative dimension was not evidenced in the literature (Fig. 1).

The managerial dimension mainly includes the practices of organizing, planning, and supervising the actions of technicians, assistants, and community agents; holding and participating in meetings; and setting agendas. In general, nurses are also the managers of the health units, and this dimension occupies a large portion of the nurses' working time, reinforcing the idea that much of what nurses do is invisible [25-31].

The purpose of health surveillance is to constantly observe and analyze the population's health status to control health determinants, risks, and harm. This dimension includes actions to promote, prevent, and control illnesses and vulnerabilities over the area of operation, such as active searches, notification of events in public health interest, and vaccination campaigns [26-33]. The educational dimension, which is part of the other dimensions, encompasses health education actions for individuals, families, and groups; permanent education for other team professionals; and student mentorship [25-35].

Clinical practices-care provided directly to the user-are most performed by nurses and occur mainly in the context of spontaneous demand and nursing consultations, either in the unit or during home visits. Nursing consultations constitute a strategy that favors performing the actions prescribed in programs that integrate PHC. Moreover, these actions are the main reasons why nurses provide care, such as management of chronic non-communicable diseases, sexual and reproductive health, women's health, and prenatal care [25-44]. In this dimension, the most common technical procedures include the administration of vaccines and medications, the collection of oncotic colpocytology (Pap smear) and test materials, and the application of dressings and glucose tests. The most common prescriptions are for dressings, and-according to clinical protocols-for medication, supplements, and laboratory tests, especially within prenatal care and diabetes and hypertension management [27-30, 35, 36, 39-46].

A study [40] conducted on more than 2500 nurses working in PHC found that these nurses knew how to perform more activities in addition to those that they carried out in their workplace. The reasons for their limited work practice were the lack of municipal clinical protocols and/or the existence of restrictive measures by the professional council. The nurses who performed exclusive medical activities-abscess drainage (30\%), sutures (5\%), and local anesthesia (6\%)-did so either because there was a lack of doctors in the units or because the doctors did not have the technical skills to perform them $[29,39,40]$.

\section{Education}

In terms of the practices taught in undergraduate nursing programs, we determined that students are prepared to carry out various actions that are legally and socially recognized as nurse's activities. Meanwhile, the practices that nurses are allowed to perform, but are historically understood to be the physician's responsibility, were mostly classified as capacities that were not covered or only partially covered by programs (Table 3 ). In face-toface interviews, the evaluation of the last set of actions, especially prescribing medication, was preceded by justifications based on the perception that these functions go beyond the nurse's scope of practice.

"We do not teach how to prescribe any medication, not even those provided for in the protocols. It falls under the physician's responsibility [...]. The nurse performs diagnostic tests because it is technical, but interpreting and making diagnoses does not fall under the nurse's responsibility either." (Southern macroregion)

"There is the issue of primary care protocols that 
Table 2 Synthesis of the set of permitted and prohibited practices for Brazilian nurses based on legal provisions

\section{Provision}

Law No. 7.498/1986_-Professional Practice Law
Resolutions issued by the Federal Nursing Council

Guidelines, manuals, and thematic journals orienting primary care, issued by the Ministry of Health

\section{Practices}

Authorized practices

Nurse's exclusive practices

a) Manage entities and head nursing services and units

b) Plan, organize, coordinate, execute, and evaluate nursing assistance services

c) Consult, audit, and issue opinions on nursing matters

d) Nursing consultations

e) Prescribe nursing assistance

f) Direct nursing care for critically ill patients at risk of death

g) More technically complex nursing care that requires scientific knowledge and the ability to make immediate decisions

The nurse as a member of the healthcare team (shared practices)

a) Participates in the planning, execution, and evaluation of healthcare programs and plans

b) Prescribes drugs provided for in public healthcare programs and routinely approved by the healthcare institution

c) Prevents and systematically controls nosocomial infection, communicable diseases in general, and harm that may be caused to patients

d) Nursing care for pregnant women, prenatal and postnatal care

e) Monitor progress and labor and delivery

f) Delivery without dystocia

g) Education that aims to improve the population's health

The obstetric nurse as a member of the healthcare team (shared practices)

a) Provides assistance in prenatal care and in normal childbirth

b) Identifies obstetric dystocia and takes measures until the physician's arrival

c) Performs episiotomy and episiorrhaphy and applies local anesthesia, when necessary

Nurse's exclusive practices within the nursing team

a) The nurse can request routine and complementary exams

b) Collect material for oncotic colpocytology by Pap smear

c) Classify risk and prioritize assistance in urgent care services

d) Insert urinary catheters

Nurse's specific practices in primary care depending on local clinical protocols

a) Provide healthcare to individuals and families linked to teams in the unit, at home, and in other community spaces

b) Perform nursing consultations and procedures, request complementary exams, prescribe medications according to protocols, clinical and therapeutic guidelines, or other technical norms established by the federal, state, or municipal administrator, observing the legal provisions for the profession

c) Receive patients with qualified listening and risk classification

d) Conduct group activities and refer patients to other services, when necessary

e) Perform prenatal consultations for low-risk pregnant women, alternating with the presence of the physician

f) Perform rapid tests

g) Perform clinical breast examinations and collections for cervical cytopathological examinations

h) Family planning and prescription of contraceptive methods (except definitive ones)

i) Normal delivery without dystocia

Prohibited practices 
Table 2 (continued)

\begin{tabular}{|c|c|}
\hline Provision & Practices \\
\hline \multirow[t]{7}{*}{$\begin{array}{l}\text { Nursing Code of Ethics and resolutions issued by the Federal Nursing } \\
\text { Council }\end{array}$} & $\begin{array}{l}\text { a) Deny nursing care in urgent, emergency, epidemic, disaster, and cata- } \\
\text { strophic situations }\end{array}$ \\
\hline & $\begin{array}{l}\text { b) Perform surgical acts, except in emergency situations or in those } \\
\text { expressly authorized by law, provided that the nurse has the necessary } \\
\text { technical/scientific skills }\end{array}$ \\
\hline & $\begin{array}{l}\text { c) Prescribe medications that are not established in public healthcare } \\
\text { programs and/or in routines approved by a healthcare institution, except } \\
\text { in emergency situations }\end{array}$ \\
\hline & $\begin{array}{l}\text { d) Provide services that are, by their nature, the responsibility of another } \\
\text { professional, except in emergencies or those expressly authorized by } \\
\text { current legislation }\end{array}$ \\
\hline & e) Delegate exclusive activities to other members of the healthcare team \\
\hline & $\begin{array}{l}\text { f) Apply sutures, except in urgent cases where there is an imminent and } \\
\text { serious risk of life }\end{array}$ \\
\hline & g) Comply with a remote medical prescription or after the expiration date \\
\hline
\end{tabular}

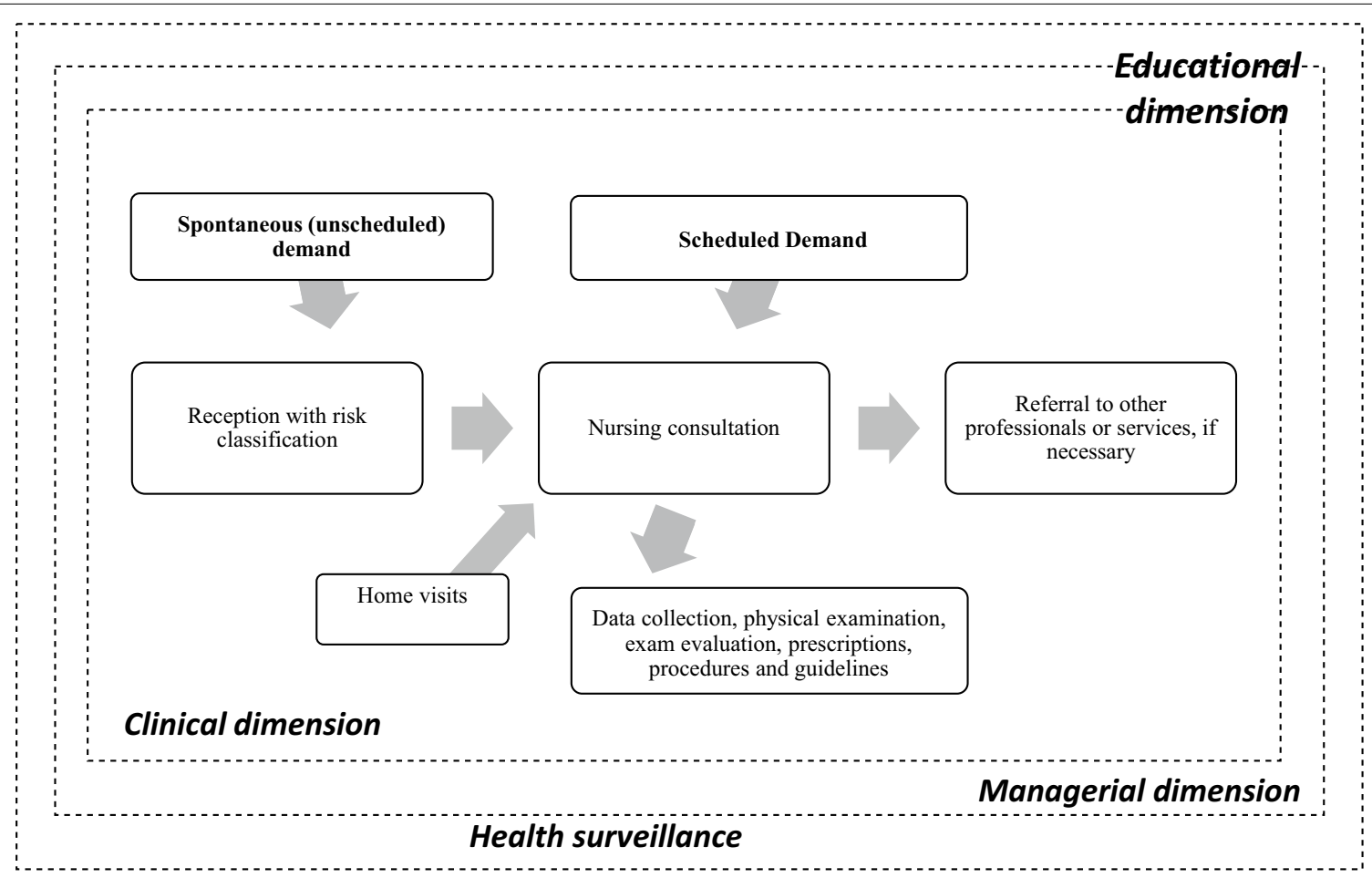

Fig. 1 Dimensions of practices performed by Brazilian nurses in primary healthcare

dictate what nurses can do. But, seriously, the nurse has to do what a nurse has to do. We cannot be concerned with what the other person does. There is no point in wanting to prescribe medication if one does not even know how to make a nursing diagnosis." (Southeastern macroregion)
Moreover, we found that students are not prepared to perform exclusive medical activities. Nevertheless, directors recognized that during educational internships, students accompany nurses who performed such activities, especially in rural areas. 
Table 3 Percentage of nursing programs according to the preparation of students for the development of actions $(n=110)$

\begin{tabular}{|c|c|c|c|}
\hline Actions and procedures & Prepare & Partially prepare & Do not prepare \\
\hline \multicolumn{4}{|l|}{ Actions legally assigned and historically recognized as nurses' activities } \\
\hline Insert nasogastric, nasoenteric, and urethral intubation & 99.1 & 1.0 & 0.0 \\
\hline Apply dressings & 99.1 & 1.0 & 0.0 \\
\hline Administer medications & 99.1 & 0.9 & 0.0 \\
\hline Conduct health education groups & 98.2 & 0.9 & 0.9 \\
\hline Execute health promotion actions & 97.2 & 2.8 & 0.0 \\
\hline Administer vaccines & 96.7 & 2.1 & 1.1 \\
\hline Plan and execute vaccination campaigns & 96.3 & 2.8 & 1.0 \\
\hline Perform compulsory notifications & 95.7 & 4.3 & 0.0 \\
\hline Execute family planning & 95.3 & 3.8 & 1.0 \\
\hline Perform Pap smear & 94.5 & 3.7 & 1.9 \\
\hline Perform pediatric consultation & 93.6 & 4.6 & 1.8 \\
\hline Interpret Pap smear & 91.5 & 3.2 & 5.3 \\
\hline Perform low-risk prenatal care & 90.9 & 9.1 & 0.0 \\
\hline Receive patients with risk classification & 87.2 & 11.0 & 1.8 \\
\hline Prescribe dressings & 83.9 & 10.7 & 5.4 \\
\hline Perform electrocardiograms & 83.2 & 9.3 & 7.5 \\
\hline Insert peripheral venous catheters & 81.3 & 10.2 & 8.4 \\
\hline Perform artery punctures & 76.3 & 10.7 & 12.9 \\
\hline Average & 92.2 & 5.1 & 2.7 \\
\hline \multicolumn{4}{|l|}{ Actions legally permitted for nurses but historically recognized as exclusive to the physician ${ }^{a}$} \\
\hline Interpret laboratory tests & 75.2 & 22.0 & 2.7 \\
\hline Interpret imaging tests & 53.2 & 25.6 & 21.1 \\
\hline Request laboratory tests & 47.7 & 29.4 & 22.9 \\
\hline Prescribe medications provided for in institutional protocols & 46.7 & 46.7 & 6.7 \\
\hline Perform normal deliveries & 42.1 & 18.7 & 39.2 \\
\hline Request imaging tests & 23.1 & 24.1 & 52.7 \\
\hline Prescribe anthelmintics & 19.6 & 15.9 & 64.5 \\
\hline Prescribe antifungals & 13.1 & 9.8 & 77.1 \\
\hline Prescribe anti-inflammatory drugs & 12.0 & 6.5 & 81.5 \\
\hline Prescribe antibiotics & 9.3 & 15.9 & 74.7 \\
\hline Average & 34.2 & 21.5 & 44.3 \\
\hline \multicolumn{4}{|l|}{ Actions exclusive to the physician } \\
\hline Perform abscess drainage & 47.1 & 14.1 & 38.7 \\
\hline Communicate nosological diagnoses to patients ${ }^{\mathrm{b}}$ & 26.9 & 12.9 & 60.2 \\
\hline Prescribe medications for people with chronic illness diagnosed by the physician & 17.6 & 18.5 & 63.9 \\
\hline Renew medical prescriptions & 12.8 & 5.3 & 81.9 \\
\hline Apply sutures ${ }^{c}$ & 11.1 & 17.6 & 71.3 \\
\hline Perform local anesthesia ${ }^{c}$ & 9.7 & 7.5 & 82.8 \\
\hline Confirm death & 8.7 & 7.6 & 83.7 \\
\hline Prescribe psychoactive drugs & 5.4 & 3.3 & 91.3 \\
\hline Make nosological diagnoses ${ }^{b}$ & 4.3 & 2.1 & 93.6 \\
\hline Average & 16.0 & 9.9 & 74.2 \\
\hline
\end{tabular}

a Legally permitted by the Federal Nursing Council and the Ministry of Health but subject to the local administrator's authorization through the creation of nursing protocols

${ }^{b}$ According to the Law on the Professional Practice of Medicine, these practices are not exclusive to the physician, but judicial decisions have ruled in favor of the understanding that the physician is the only professional legally authorized to perform diagnoses. Although it is not exclusive, it can only be shared with other professions by way of federal laws and never by council resolutions or municipal or state laws. Within PHC, these actions can be performed by nurses in services where clinical nursing protocols are in place, but they are limited to common diseases that are not serious (e.g., worm infestations, dermatitis, sexually transmitted infections) ' Obstetric nurses can perform these actions within the scope of gynecological assistance (perform episiotomy and episiorrhaphy with the application of local anesthesia) 
"In the countryside, many nurses perform medical actions in the absence of a physician." (Midwestern macroregion)

"My students accompany nurses who prescribe medication, apply sutures. And they will surely have to perform these procedures out of necessity after they graduate. Will they see a person with tuberculosis or pneumonia and, knowing the appropriate medication, not prescribe it, because it is not within their responsibility? Can I characterize that as what, neglect?" (Northern macroregion)

\section{Discussion and conclusion}

The process of introducing APN in Brazil remains in the initial stages of discussion. In addition, the first studies on the subject remain in the early stages of development, the results of which may define the APN model for implementation. Jhpiego [47] proposes initiating the operationalization of the model by defining its scope of practice, which includes describing the professional's activities, responsibilities, and level of authority based on a situational analysis of the demands of the healthcare system. Subsequently, the skills required for safe, effective practice and the policies that ensure professional autonomy must be defined.

In Brazilian PHC, common illnesses, which are generally benign, self-limiting, and minor, and social illnesses, occur more frequently in a community. Despite this plurality, demand is concentrated on a few problems or reasons for consultation [48], the most frequent being chronic diseases, especially non-insulin-dependent diabetes and uncomplicated arterial hypertension; family planning; prenatal care; and health maintenance/disease prevention [48-51]. These demands require developing nursing actions that align with the skill set in the curricular guidelines and are anchored in the scope of practice authorized by the legislation and primary care programs guidelines.

This study demonstrates that these demands correspond with the main reasons for the nurse's care in PHC. They perform a set of clinical, managerial, educational, and health surveillance activities, including advanced practices, according to international models [10-12]. Although to a lesser extent, nurses also perform exclusive medical practices in the absence of a physician in health units. Furthermore, this study indicates that most undergraduate programs do not fully prepare students to adequately execute advanced tasks. These results corroborate with the findings of other studies conducted on the nursing field $[40,52]$.
This gap in the training process can be attributed to several factors, such as: (a) the lack of articulation between educational institutions and health services, resulting in curricula that do not correspond to the training demands required by the health context $[17,18]$; (b) although extensive, the workload of bachelor's degree courses is insufficient to promote the development of all the skills required by the health system $[18,53]$; (c) advanced practice nursing is a little explored and controversial subject in Brazil. The implementation of these practices is not unanimous among nurses, and it is poorly understood by other professionals, health managers, nursing professors and SUS users [19, 54]; (d) the training regulations are generic, allowing different interpretations, and are obsolete, as they no longer reflect the social and health needs of Brazil [18, 53]; (e) some nurses and nursing professors believe that the profession has distanced itself from its real attributions in the care process, and it is not up to them to incorporate other activities [19]; (f) the bachelor's degree courses in nursing are mostly private $(90 \%)$, whose teaching has been characterized by the precariousness of practical activities. In this aspect, there is a differentiated training in public and private schools that neither serve the interests of the profession nor the training of professionals for the SUS [53].

Although it is verified that there has been an increase in nurses' autonomy within the PHC over the last decades, notably due to the expansion of their clinical performance supported by legal documents, their work is still technically subordinate to that of the physician and is thus socially understood [55]. This finding reaffirms that the training model is still centered on clinical specialties and guided by the logic of "professional tribalism", as opposed to the logic of training and work in PHC, which is based on health needs population, interdisciplinarity and professional collaboration [56, 57]. All these factors, to a lesser or greater degree, are reflected in the curricula and pedagogical practices of bachelor's degree in nursing.

Despite this, advanced practices seem to already be occurring in Brazil. There are national documents that ensure and authorize nursing graduates to conduct these practices, thus rendering the municipalities to prepare the appropriate clinical guidelines for local needs. The guidelines must comply with the legal and ethical principles of the profession and SUS rules and regulations, consider the best available evidence, and enable professional autonomy. Furthermore, once deficiencies in the training

\footnotetext{
2 Tendency of each profession to act in isolation. It is the result of the culture of separate training, with an emphasis on the development of specific skills, which ends up building very rigid professional identities and which, historically, has been configured as a barrier to communication between professionals of different categories.
} 


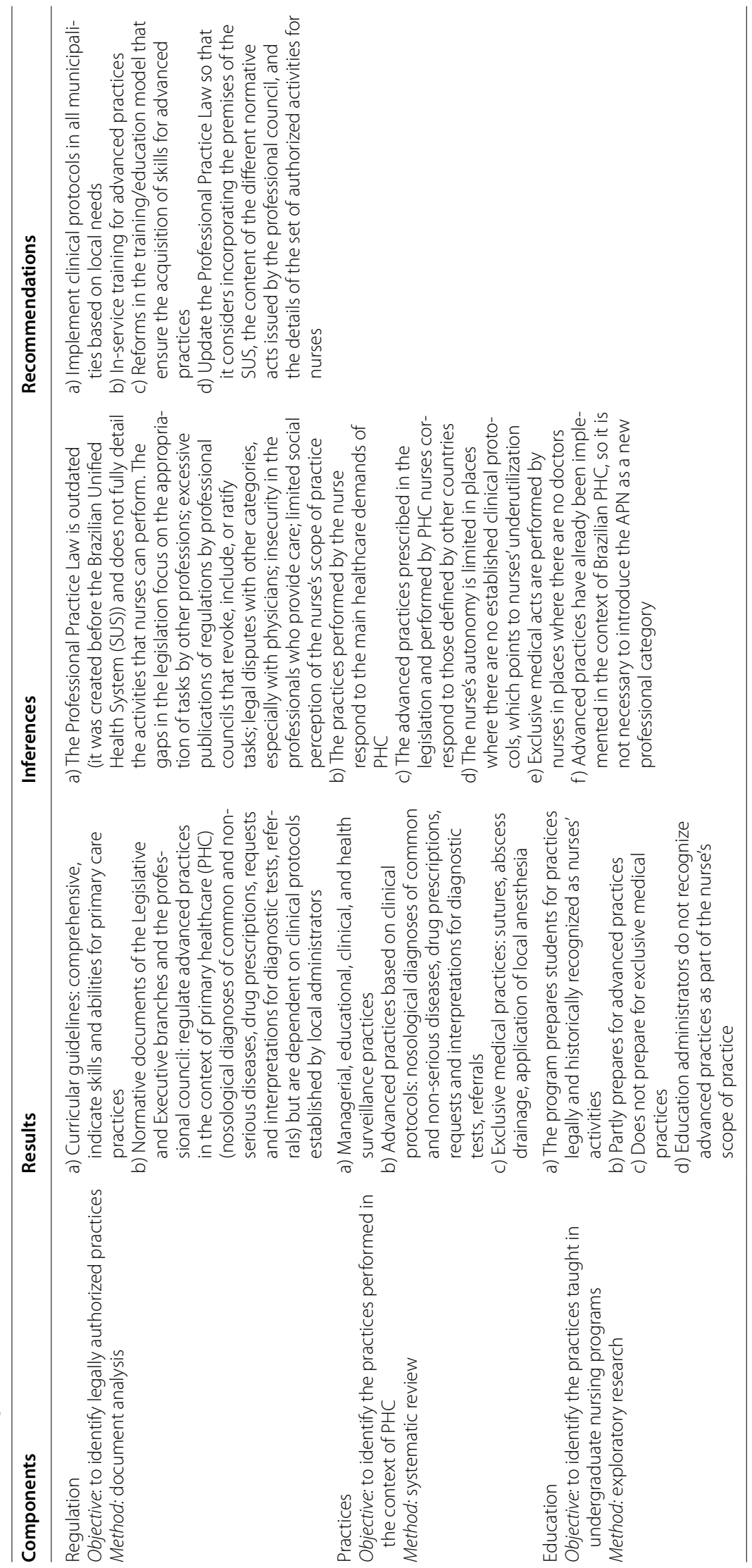




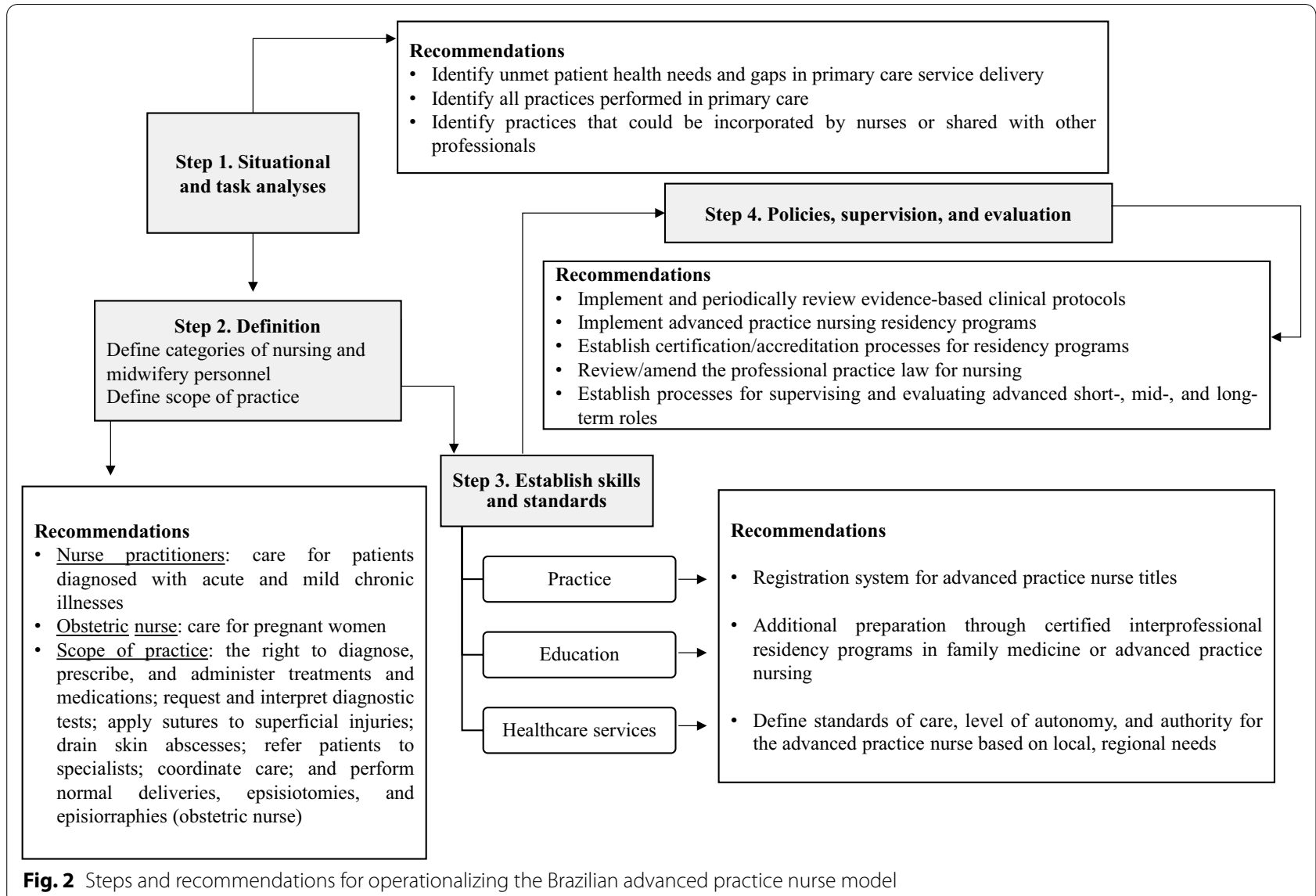

Fig. 2 Steps and recommendations for operationalizing the Brazilian advanced practice nurse model

process have been verified, the current education model should undergo reforms to incorporate the skills compatible with the regulated advanced practices. There is already a need to expand the curricular contents of pharmacology, pathophysiology, and evidence-based practice $[52,58]$.

Immediately, additional training through interprofessional continuing education processes is recommended for professionals who already work in PHC, to ensure the quality of care and the professional's safety in their performance of advanced practices. It is also imperative to update the normative acts that regulate education and the scope of practice, as they are outdated and too general in terms of describing the skills and the scope of advanced practices (Table 4 ).

If Brazil decides to introduce the international APN model, either by safeguarding current advanced practices or by expanding them, the process would be more arduous and time-consuming. It would require reforming the current model of professional regulation in order to comply with the countless recommendations that sustain APN characteristics, such as additional educational preparation in certified programs at the professional master's degree level, protected titles, and specific APN regulations $[8,12]$. Figure 2 proposes the steps to operationalize this APN model.

Unlike international recommendations, we do not believe that the professional master's degree is the most appropriate level of training in the Brazilian context. These programs are found mostly in large urban centers and are strongly influenced by academic models that contrast with the proposal to train nurses in the exercise of professional, transformative practice [59]. We suggest seeking additional training in lato sensu graduate programs, ${ }^{3}$ especially in interprofessional family medicine residency programs.

\footnotetext{
${ }^{3}$ In Brazil, there are two types of postgraduate; lato sensu, which encompasses specialization and residency programs in one area of study, mostly addressed to professional practice, and stricto sensu, which means a Master or Doctorate, encompassing broader and profound activities of scientific research.
} 
Regardless of the adoption of the APN model, other future objectives in Brazil include fortifying education and interprofessional work and permanent education actions, wage reform, investment in infrastructure and working conditions, and greater control over the formation and quality of undergraduate programs. Moreover, a greater governmental role is necessary in the regulation of healthcare professions, specifically to mitigate weaknesses of laws on the exercise of professions and to resolve corporate clashes over disputes regarding scope of practice [60].

Expanded, fluid, and flexible regulatory legislation could be defined based on inter-professionalism and task sharing, thus establishing common goals for all healthcare professions and specific regulations for a given profession. This model could provide flexibility in the division of healthcare work by adopting public interest as its guiding principle, rather than the profession's organizations, its self-regulation, or the monopoly imposed by professional categories.

\section{Abbreviations}

APN: Advanced practice nurse; COFEN: Federal Nursing Council (Conselho Federal de Enfermagem, in Portuguese); PHC: Primary healthcare; SUS: Unified Health System (Sistema Único de Saúde, in Portuguese.

\section{Supplementary Information}

The online version contains supplementary material available at https://doi. org/10.1186/s12960-021-00632-w.

Additional file 1: Scoping review. Detailed information about the scoping review. Table S1. Terms selected for research. Table S2. Search strategies. Table S3. Characterization variables in the set of publications. Table S4. Indexing data, aims, and methods of the set of publications. Table S5. Set of practices carried out by Primary Health Care nurses. Table S6. Technical procedures and prescriptions carried out by Primary Health Care nurses.

Figure S1. Flowchart of the refinement process.

\section{Acknowledgements}

Not applicable.

\section{Authors' contributions}

All authors contributed to the conception of the study and data analysis. CM was responsible for data collection and prepared the manuscript. All authors read and approved the final manuscript.

\section{Funding}

The national exploratory study is part of the 'Regulation of Work and Health Professions' research, which was requested by the Brazilian Ministry of Health and funded by the Pan American Health Organization (Letter Agreement BR/ LOA/1400070.001). These bodies did not participate in the data collection and analysis or in the writing of this manuscript. This article was submitted to 'Health workforce: Accreditation of education and regulation of practice' thematic series sponsored by the Foundation for Advancement of International Medical Education and Research.

\section{Availability of data and materials}

All data analyzed during this study are included in this published article and its supplementary information files.

\section{Declarations}

Ethics approval and consent to participate

Ethics approval was obtained from Rio de Janeiro State University Research Ethics Committee (Reference No: 1.248.858). All respondents signed a participation consent form.

\section{Consent for publication}

Not applicable.

\section{Competing interests}

The authors declare no competing interests.

\section{Author details}

${ }^{1}$ Department of Policy, Management and Health, School of Public Health, University of São Paulo (FSP/USP), Av. Dr. Arnaldo, 715, São Paulo, SP 01246-904, Brazil. ${ }^{2}$ Institute of Social Medicine, Rio de Janeiro State University (IMS/Uerj), Rio de Janeiro, Brazil.

Received: 4 May 2021 Accepted: 9 July 2021

Published online: 22 July 2021

\section{References}

1. Paim J, Travassos C, Almeida C, Bahia L, Macinko J. The Brazilian health system: history, advances, and challenges. Lancet. 2011;377:1778-97. https://doi.org/10.1016/S0140-6736(11)60054-8.

2. Santos LM, Oliveira A, Trindade JS, Barreto IV, Palmeira PA, Comes Y, et al. Implementation research: towards universal health coverage with more doctors in Brazil. Bull World Health Organ. 2017;95(2):103-12. https://doi. org/10.2471/BLT.16.178236.

3. Andrade MV, Coelho AQ, Xavier Neto M, de Carvalho LR, Atun R, Castro $M C$. Transition to universal primary health care coverage in Brazil: analysis of uptake and expansion patterns of Brazil's Family Health Strategy (1998-2012). PLOS ONE. 2018;13(8): e0201723. https://doi.org/10.1371/ journal.pone.0201723.

4. Fertonani HP, Pires DEP, Biff D, Scherer MDA. The health care model: concepts and challenges for primary health care in Brazil. Ciênc Saúde Coletiva. 2015;20(6):1869-78. https://doi.org/10.1590/1413-81232015206. 13272014.

5. Figueiredo AM, McKinley DW, Massuda A, Azevedo GD. Evaluating medical education regulation changes in Brazil: workforce impact. Hum Resour Health. 2021;19:33. https://doi.org/10.1186/s12960-021-00580-5.

6. Pierantoni R, Magnago C. Tendencias de las graduaciones en Salud en el Brasil: análisis de la oferta en el contexto del Mercosur. Divulg Saude Debate. 2017;57:30-43.

7. Instituto Nacional de Estudos e Pesquisas Educacionais Anísio Teixeira Sinopse estatística da educação superior 2019. Brasília: Inep; 2020. http:// portal.inep.gov.br/basica-censo-escolar-sinopse-sinopse. Accessed 28 Mar 2020.

8. Organization PAH. Expanding the roles of nurses in primary health care. Washington, D.C.: PAHO; 2018.

9. Delamaire M, Lafortune G. Nurses in advanced roles. A description and evaluation of experiences in 12 developed countries. Paris: OECD; 2010 (OECD Health Working Papers No 54). https://doi.org/10.1787/5kmbr cfms5g7-en.

10. Sánchez-Gómez MB, Ramos-Santana S, Gómez-Salgado J, Sánchez-Nicolás F, Moreno-Garriga C, Duarte-Clíments G. Benefits of advanced practice nursing for its expansion in the spanish context. Int J Environ Res Public Health. 2019;16(5):680. https://doi.org/10.3390/ijerph16050680.

11. Swan M, Ferguson S, Chang A, Larson E, Smaldone A. Quality of primary care by advanced practice nurses: a systematic review. Int J Qual Health Care. 2015;27(5):396-404. https://doi.org/10.1093/intqhc/mzv054.

12. International Council of Nurses. Guidelines on advanced practice nursing. Geneva: ICN; 2020.

13. Eriksson I, Lindblad M, Möller U, Gillsjö C. Holistic health care: patients' experiences of health care provided by an advanced practice nurse. Int J Nurs Pract. 2018;24(1): e12603. https://doi.org/10.1111/ijn.12603. 
14. Côté N, Freeman A, Jean E, Denis JL. New understanding of primary health care nurse practitioner role optimisation: the dynamic relationship between the context and work meaning. BMC Health Serv Res. 2019;19(1):882. https://doi.org/10.1186/s12913-019-4731-8.

15. Oliveira JLC, Toso BRGO, Matsuda LM. Advanced practices for care management: reflections on the Brazilian nursing. Rev Bras Enferm. 2018;71(4):2060-5. https://doi.org/10.1590/0034-7167-2017-0115.

16. Tricco AC, Lillie E, Zarin W, O'Brien KK, Colquhoun H, Levac D, et al. PRISMA extension for scoping reviews (PRISMA-SCR): checklist and explanation. Ann Intern Med. 2018;169(7):467-73. https://doi.org/10.7326/ M18-0850.

17. Magnago C, Pierantoni CR. Nursing training and their approximation to the assumptions of the National Curriculum Guidelines and Primary Health Care. Ciênc Saúde Coletiva. 2020;25(1):15-24. https://doi.org/10. 1590/1413-81232020251.28372019.

18. Magnago C, Pierantoni CR, Carvalho CL, Girardi SN. Nurse training in health in different regions in Brazil. Rev Bras Saude Mater Infant. 2017;17(Suppl 1):S219-28. https://doi.org/10.1590/1806-9304201700 s100010.

19. Magnago C, Pierantoni C. Práticas avançadas de enfermagem na atenção primária: estudo de opinião. Rev Recien. 2021;11(33):251-9. https://doi.org/10.24276/rrecien2021.11.33.251-259.

20. Santos KS, Ribeiro MC, Queiroga DEU, Silva IAP, Ferreira SMS. The use of multiple triangulations as a validation strategy in a qualitative study. Ciênc Saúde Coletiva. 2020;25(2):655-64. https://doi.org/10.1590/141381232020252.12302018.

21. Aith FMA, Germani ACC, Balbinot R, Dallari SG. Regulação do exercício de profissões de saúde: fragmentação e complexidade do modelo regulatório brasileiro e desafios para seu aperfeiçoamento. Rev Direito Sanit. 2018;19(2):198-2018.

22. Lei nº.7.498, de 25 de junho de 1986. Dispõe sobre a regulamentação do exercício da enfermagem, e dá outras providências. Brasília, DF: Diário Oficial da República Federativa do Brasil; 1986.

23. Ministério da Educação. Resolução CNE/CES no. 03, de 07 de novembro de 2001. Institui Diretrizes Curriculares Nacionais do Curso de Graduação em Enfermagem. Diário Oficial da República Federativa do Brasil, Brasília; 2001

24. Ministério da Saúde. Portaria no 2.436, de 21 de setembro de 2017. Aprova a Política Nacional de Atenção Básica. Brasília, DF: Diário Oficial da República Federativa do Brasil; 2017.

25. Mendes M, Trindade LL, Pires DEP, Martins MMFPS, Ribeiro OMPOL, Forte ECN, et al. Nursing practices in the family health strategy in Brazil: interfaces with illness. Rev Gaúcha Enferm. 2021;42(esp):20200117. https://doi.org/10.1590/1983-1447.2021.20200117.

26. Bonfim D, Fugulin FMT, Laus AM, Peduzzi M, Gaidzinski RR. Time standards of nursing in Primary Health Care: an observational study. Rev Esc Enferm USP. 2016;50(1):118-26. https://doi.org/10.1590/S0080-62342 0160000100016.

27. Lemos PFS. Ações de saúde realizadas por enfermeiros e o uso de protocolos clínicos e diretrizes terapêuticas no contexto atual da Estratégia Saúde da Família no município do Rio de Janeiro [thesis]. Rio de Janeiro: Universidade do Estado do Rio de Janeiro; 2017.

28. Corrêa VAF, Acioli S, Tinoco TF. The care of nurses in the Family Health Strategy: practices and theoretical foundation. Rev Bras Enferm. 2018;71(suppl 6):2767-74. https://doi.org/10.1590/ 0034-7167-2018-0383.

29. Koster I. O exercício profissional da enfermagem no âmbito da Atenção Primária à Saúde no Brasil [thesis]. Rio de Janeiro: Fundação Oswaldo Cruz; 2019.

30. Forte ECN, Pires DEP, Scherer MDA, Soratto J. Does the nurses' work change when the Primary Health Care change? Tempus, Actas de Saúde Colet. 2018;11(2):53-68.

31. Paula M, Peres AM, Bernadino E, Eduardo EA, Sade PMC, Larocca LM. Characteristics of the nurses' work process in the family health strategy. Rev Min Enferm. 2014;18(2):454-70. https://doi.org/10.5935/14152762.20140034

32. Amoras JAB. Ações de saúde da mulher desenvolvidas pela equipe de enfermagem da Estratégia Saúde da Família no Mato Grosso do Sul [dissertation]. Campo Grande: Universidade Federal de Mato Grosso do Sul; 2017.
33. Tavares RE, Tocantins FR. Nursing actions in primary care and the control of diseases preventable through vaccines. Rev Bras Enferm. 2015;68(5):803-9. https://doi.org/10.1590/0034-7167.2015680506i.

34. Ferraccioli P, Acioli S. The different dimensions of care in practice held by nurses in primary care. Rev Fund Care Online. 2017;9(1):28-36. https://doi.org/10.9789/2175-5361.2017.v9i1.28-36.

35. Acioli S, Kebian LVA, Faria MGA, Ferraccioli P, Correa VAF. Care practices: the role of nurses in primary health care. UERJ Nurs J. 2015;22(5):63742. https://doi.org/10.12957/reuerj.2014.12338.

36. Duarte HSJ, Mamede MV. Actions performed by the nursing team in prenatal care at primary health care setting, Cuiabá, Brazil. Cienc Enferm. 2013;19(1):117-29. https://doi.org/10.4067/S0717-9553201300 0100011.

37. Becker RM, Heidemann ITSB, Meirelles BHS, Costa MFBNA, Antonini FO, Durand MK. Nursing care practices for people with chronic noncommunicable diseases. Rev Bras Enferm. 2018;71(suppl 6):2643-9. https:// doi.org/10.1590/0034-7167-2017-0799

38. Vieira DS, Santos NCCB, Nascimento JA, Collet N, Toso BRGO, Reichert APS. Nursing practices in child care consultation in the Estratégia Saúde da Família. Texto Contexto Enferm. 2018;27(4): e4890017. https://doi.org/10.1590/0104-07072018004890017.

39. Girardi SN, Stralen ACSV, Lauar TV, Cella JN, Araújo JF, Pierantoni CR, et al. Scope of practice in Primary Care: physicians and nurses in five health regions in Brazil. Rev Bras Saude Mater Infant. 2017;17(1):17184. https://doi.org/10.1590/1806-9304201700s100008.

40. Pierantoni CR, Girardi SN (Coord.). Regulação do Trabalho e das Profissões em Saúde [Research Report]. Rio de Janeiro: ObservaRH/IMS/ UERJ, EPSM/NESCON/UFMG; 2017.

41. Narchi NZ. Exercise of essential competencies for midwifery care by nurses in São Paulo, Brazil. Midwifery. 2011;27(1):23-9. https://doi.org/ 10.1016/j.midw.2009.04.007.

42. Peduzzi M, Aguiar C, Lima AMV, Montanari PM, Leonello VM, Oliveira MR. Expansion of the interprofessional clinical practice of Primary Care nurses. Rev Bras Enferm. 2019;72(Suppl 1):114-21. https://doi.org/10. 1590/0034-7167-2017-0759.

43. Baptista RS, Dutra MOM, Coura AS, Stélio SF. Prenatal care: essential actions developed by nurses. Enferm Glob. 2015;14(40):96-111.

44. Nunes PS, Marques MB, Machado ALG, Silva MJ. Descrição das práticas dos Enfermeiros da atenção básica direcionadas para idosos diabéticos. Cogitare Enferm. 2009;14(4):682-8.

45. Pilger C, Dias JF, Kanawava C, Baratieri T, Carreira L. Compreensão sobre o envelhecimento e ações desenvolvidas pelo enfermeiro na atenção primária à saúde. Cienc Enferm. 2013;19(1):61-73. https://doi.org/10. 4067/S0717-95532013000100006.

46. Kahl C, Meirelles BHS, Cunha KS, Bernardo MS, Erdmann AL. Contributions of the nurse's clinical practice to Primary Care. Rev Bras Enferm. 2019;72(2):354-9. https://doi.org/10.1590/0034-7167-2018-0348.

47. Jhpiego. Health Care Professional and Occupational Regulation Toolkit. Baltimore, Johns Hopkins Program for International Education in Gynecology and Obstetrics; 2013. https://reprolineplus.org/resou rces/health-care-professional-and-occupational-regulation-toolkit. Accessed 25 Mar 2021.

48. Mendes EV. A construção social da Atenção Primária à Saúde. Brasília: Conselho Nacional de Secretários de Saúde; 2015.

49. Gusso GDF. Diagnóstico da demanda em Florianópolis utilizando a Classificação Internacional da Atenção Primária: 2a edição (CIAP-2) [thesis]. São Paulo: Universidade de São Paulo; 2009.

50. Pimentel IRS. Caracterização da demanda em uma Unidade de Saúde da Família. Rev Bras Med Fam Comunidade. 2011;6(20):175-81. https:// doi.org/10.5712/rbmfc6(20)95.

51. Esperança AC, Cavalcante RB, Marcolino C. Estudo da demanda espontânea em uma unidade de saúde da família de uma cidade de médio porte do interior de Minas Gerais, Brasil. Rev Min Enf. 2006;10(1):30-6.

52. Martiniano CS, Marcolino EC, Souza MB, Coelho AA, Arcêncio RA, Fronteira l, et al. The gap between training and practice of prescribing of drugs by nurses in the primary health care: a case study in Brazil. Nurse Educ Today. 2016;36:304-9. https://doi.org/10.1016/j.nedt.2015.07.017.

53. Toso BRGO, Padilha MI, Breda KL. The euphemism of good practice or advanced nursing practice. Esc Anna Nery. 2019;23(3): e20180385. https://doi.org/10.1590/2177-9465-EAN-2018-0385. 
54. Rewa T, Miranda Neto MV, Bonfim D, Leonello VM, Oliveira MAC. Advanced nursing practices: perception of graduates of the residency and professional master's programs. Acta Paul Enferm. 2019;32(3):25460. https://doi.org/10.1590/1982-0194201900035.

55. Pereira JG, Oliveira MAC. Nurses' autonomy in primary care: from collaborative practices to advanced practice. Acta Paul Enferm. 2018:31(6):627-35. https://doi.org/10.1590/1982-0194201800086.

56. Weller J. Shedding new light on tribalism in health care. Med Educ. 2012:46:134-6. https://doi.org/10.1111/j.1365-2923.2011.04178.x.

57. Nascimento WG, Uchôa SAC, Coêlho AA, Clementino FS, Cosme MVB, Rosa RB, et al. Medication and test prescription by nurses: contributions to advanced practice and transformation of care. Rev Latino-Am Enfermagem. 2018;26: e3062. https://doi.org/10.1590/1518-8345. 2423-3062.

58. Parker JM, Hill MN. A review of advanced practice nursing in the United States, Canada, Australia and Hong Kong Special Administrative Region
(SAR), China. Int J Nurs Sci. 2017;4(2):196-204. https://doi.org/10. 1016/j.jinss.2017.01.002.

59. Ostermann F, Rezende F. Os mestrados profissionais em ensino das ciências da natureza no Brasil. Ciênc Educ. 2015;21(3):I-III. https://doi. org/10.1590/1516-731320150030001.

60. Cassiani SH, Zug KE. Promoting the advanced nursing practice role in Latin America. Rev Bras Enferm. 2014;67(5):673-4. https://doi.org/10. 1590/0034-7167.2014670501.

\section{Publisher's Note}

Springer Nature remains neutral with regard to jurisdictional claims in published maps and institutional affiliations.
Ready to submit your research? Choose BMC and benefit from:

- fast, convenient online submission

- thorough peer review by experienced researchers in your field

- rapid publication on acceptance

- support for research data, including large and complex data types

- gold Open Access which fosters wider collaboration and increased citations

- maximum visibility for your research: over $100 \mathrm{M}$ website views per year

At BMC, research is always in progress.

Learn more biomedcentral.com/submissions 